\title{
Biomechanical Study on Distal Filling Effects in Cementless Total Hip Replacement*
}

\author{
Soo-Won $\mathrm{CHAE}^{* *}$, Jun-Hyoung LEE** and Hyung-Yun $\mathrm{CHOI}^{* * *}$
}

\begin{abstract}
In cementless total hip replacement, initial stability of the femoral component is important in the long term fixation of the femoral stem. Initial stability is closely related to the relative displacement between the prosthesis and the cancellous bone of the proximal femur. After implantation of the prosthesis, the surrounding bone is partially shielded from load carrying and starts to resorb. Stress shielding causes the loss of the proximal bone. The stress distribution of femur must be assessed to predict stress shielding. The initial stability and the stress shielding were investigated for two loading conditions approximating a single leg stance and stair climbing. Two types of stems involving a distal filling and a distal short stem were studied by the finite element method to investigate the biomechanical distal filling effects. The distal short stem produced less stress shielding at the proximal bone than the distal filling stem, while both types of stems seemed to satisfy the initial stability requirement.
\end{abstract}

Key Words: Total Hip Replacement, Distal Filling Stem, Distal Short Stem, Stress Shielding, Initial Stability, Finite Element Analysis

\section{Introduction}

In total hip replacement(THR), the damaged hip joint is replaced with prosthesis, and this procedure allows the patient to return to his/her normal daily activities. Experimental design process of an artificial hip joint requires time consuming and difficult analysis and evaluation. However, precise three dimensional finite element models of the prosthesis and bone could be built from the CT (Computed Tomography) data, and many different prosthetic designs can be easily evaluated by numerical simulation considering various clinical issues ${ }^{(1),(2)}$. Besides, the results of experimental tests using the femurs from cadavers can be affected by the disease, race, and age of the specimens. A finite element model, however, which can represent general geometry, can be used to assess the prosthesis under specific loading conditions of actual daily $\operatorname{activities}^{(3)}$.

Unlike the cemented hip replacement, the stability of stem at the early stage after surgery is very important to

* Received 13th April, 2005 (No. 05-5033)

** Department of Mechanical Engineering, Korea University, Anam-Dong, Seongbuk-Gu, Seoul 136-701, Korea. E-mail: swchae@korea.ac.kr

*** Department of Mechanical System Design Engineering, HongIk University, Sangsu-Dong, Mapo-Gu, Seoul 121791, Korea the cementless hip replacement, in which the biological bony ingrowth is used for the fixation. This initial stability of the cementless type is an essential factor in the long term fixation of a stem and could be secured by minimization of the relative micromotions at the interface between the stem and bone. Micromotion of more than $100 \mu \mathrm{m}-$ $150 \mu \mathrm{m}$ can separate a stem from a bone and prevent bony ingrowth into the porous surface of the stem ${ }^{(4)}$. Therefore, the micromotions between stem and bone need to be minimized for long term fixation. The micromotions of the stem can also cause pain and wear of the femoral bone. The artificial hip stem "shields" the stress on the femoral bone since the relatively stiff stem shares the load that is usually carried only by the bone. Consequently, the femoral bone tries to adopt this new environment of altered stress patterns by reducing its weight with thinning or increasing its porosity ${ }^{(5),(6)}$. Rietbergen et al. ${ }^{(5)}$ studied the effect of interface condition of press-fitted hip stem on the stress shielding phenomenon by both animal test and finite element analysis. Burke et al. ${ }^{(7)}$ evaluated the initial stability of a stem by measuring the relative micro displacements for two different loading conditions such as a single leg stance and stair climbing. Skinner et al. ${ }^{(8)}$ performed the finite element stress analyses to estimate the mechanical deformation of the femur with cementless type THR for patients with various health conditions and compared the results with that of patients' mineral density 
of the femoral bones.

In this paper, finite element analyses were performed to investigate the distal filling effects of stems on the hip joint function in cementless THR surgery. Two types of hip stems were considered. The first type, the distal filling stem, was initially in precise contact with the femoral cavity at the entire surface region except at the distal end of the stem. The second type, the distal short stem, had a short distal part, and the stem was in precise contact with the femoral cavity only at the proximal part of the stem. The distal filling stem, which is more strongly fixed at the distal part than the distal short stem, often seems to have advantage in securing the initial stability. On the contrary, it has also suggested that this initial stability could be obtained sufficiently by only fixing the proximal part, and moreover the distal region of the distal short stem is less stiffly constrained than that of the distal filling stem so that the proximal region of the femur carries more stress, which is an advantage with respect to stress shielding and bone resorption. Only a few works regarding the distal short stem, namely short-stemmed femoral implant, have been made so far. One is a clinical study by B.F. Morrey ${ }^{(9)}$ and the other is an analytical study by Huiskes et al. ${ }^{(10)}$ Both studies showed the possibility that the shortstemmed femoral implant could be an attractive option. However there can be many different shapes and sizes of stems even for a short-stemmed implant. So one study on a particular shape and size of stems do not guarantee the results for generalization. In this paper more accurate finite element models based on CT images of femur have been employed than previous work. More elements with 10-noded quadratic tetrahedral elements have been used to construct the model and the contact options between a femoral bone and a stem have also been used.

Two loading cases, single leg stance and stair climbing, were applied to investigate the effect of different loading conditions on the stress patterns in the femoral bone. Only the difference in the shape between the two types of stems was considered, and therefore the analysis results should be bounded to the effect of morphological changes at the distal part of the cementless stem.

\section{Materials and Methods}

\subsection{Finite element modeling}

The original CT images of a male femoral bone were processed into 3-D surfaces by using image processing software. Sectional contours with appropriate sectional distances for finite element modeling were then extracted from the constructed surfaces as shown in Fig. 1. The sectional distances of the original CT data were $1 \mathrm{~mm}$, and for convenience, some typical sections of CT data that overally could represent the geometry of femur were selected and processed for modeling. As a result shown in Fig. 1, the sectional distances were $3 \mathrm{~mm}$ from $0-108 \mathrm{~mm}$

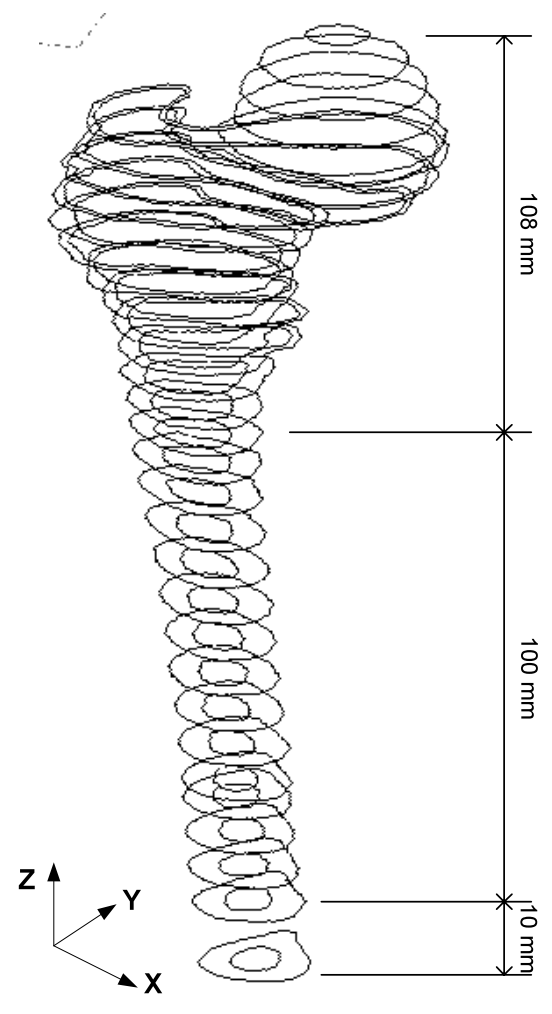

Fig. 1 Input contours of femur

Table 1 Number of tetrahedral elements constructed

\begin{tabular}{|c|c|c|c|}
\hline & & $\begin{array}{c}\text { Number of } \\
\text { tetrahedral elements }\end{array}$ & Total number of \\
\hline \multirow{2}{*}{ Femur } & cortical bone & 6369 & (femur+ stem) \\
\hline & cancellous bone & 2313 & \\
\hline \multirow{2}{*}{ Stem } & I. distal filling stem & 3391 & 12073 \\
\hline & II. distal short stem & 2435 & 11117 \\
\hline
\end{tabular}

from the top of femur, and were $4 \mathrm{~mm}$ between $108 \mathrm{~mm}-$ $208 \mathrm{~mm}$ from the top of femur, and were $10 \mathrm{~mm}$ beyond $208 \mathrm{~mm}$ from the top of femur. The finite element models were built based on these contours by using I-DEAS ${ }^{\mathrm{TM}(11)}$. To take advantage of automatic mesh generation and the high accuracy of the calculation results,10-node tetrahedral elements were employed. A finite element analysis software ABAQUS ${ }^{\mathrm{TM}(12)}$ was employed because it can model the contact surfaces of quadratic 10-node tetrahedral elements.

The total number of tetrahedral elements employed in these models is listed in Table 1. The finite element models of the femoral bone and the two types of stems constructed are shown in Figs. 2 and 3, respectively. To model contact surfaces between the femoral bone and the stems, the small-sliding contact formulation in ABAQUS ${ }^{\mathrm{TM}}$ was employed. Between the contact pairs, the stems were modeled as master surfaces and the femoral bones were modeled as slave surfaces. As shown in Fig. 3, the frictional contact region I refers to a proximal porous region, 


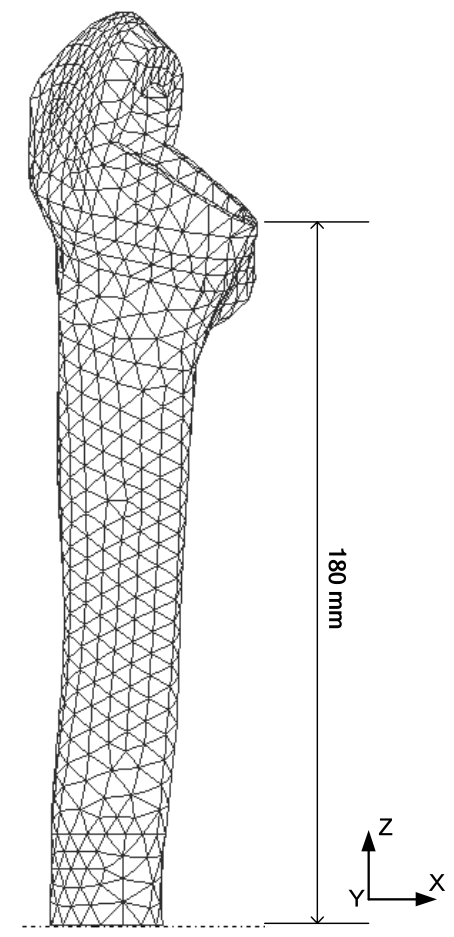

(a) Cortical bone

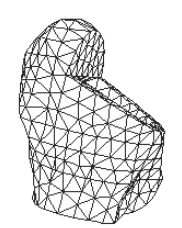

(b) Cancellous bone

Fig. 2 Finite element model of femur

which is $0 \mathrm{~mm}$ to $35 \mathrm{~mm}$ apart from the collar of a stem, while the non-frictional contact region II is defined as a distal region, which is more than $35 \mathrm{~mm}$ apart from the collar of a stem. The frictional contact region I of both stems was modeled with 282 contact elements. The nonfrictional contact region II of each stem was modeled with 483 contact elements for the distal filling stem and 133 contact elements for the distal short stem, respectively. For modeling the inner contact surface of the femur, 871 contact elements were used on the femoral side. For the distal filling stem, both of frictional contact region I and non-frictional contact region II were initially in precise contact with the femoral cavity except at a small area near the distal end of the stem; the distal short stem was initially in precise contact with the femoral cavity only at frictional contact region I. The Coulomb frictional condition at porous contact region I between a stem and a cancellous bone proposed by Keaveny and Bartel ${ }^{(13)}$ was applied with a coefficent equal to 1.73. Non-frictional contact region II was assumed to have no frictional forces, as shown in Fig. 3.

Material properties were adopted from Rubin et al. ${ }^{(14)}$ and Keaveny and Bartel ${ }^{(15)}$ as follows; Cortical bone $(E=$ $17.26 \mathrm{GPa}, v=0.29)$, cancellous bone $(E=324 \mathrm{MPa}, v=$ $0.29)$ and hip stem $(E=110 \mathrm{GPa}, v=0.3)$. Both cortical and cancellous bone materials were assumed to be isotropic and homogenous.

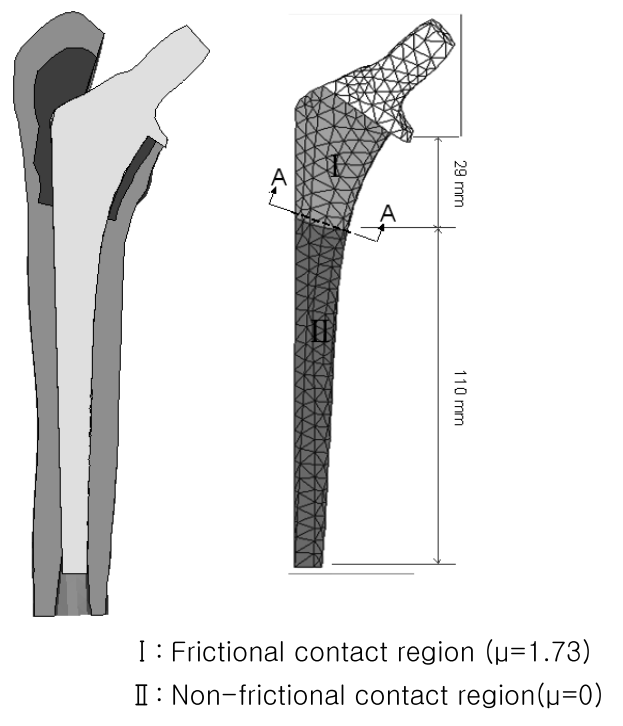

(a) Distal filling stem
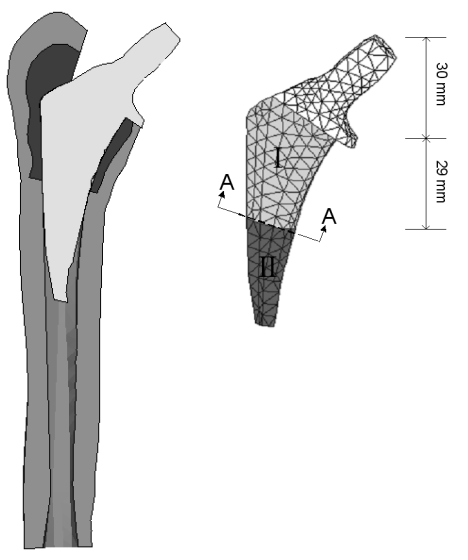

(b) Distal short stem

(c) Stem section

Fig. 3 Finite element model of stems

\section{2 Loading and boundary conditions}

As for loading conditions, both single leg stance and stair climbing conditions, were assumed. Biegler et al. ${ }^{(1)}$ and Harrigan and Harris ${ }^{(16)}$ proposed the concept of equivalent forces acting on femoral bone and stem to apply in the simulation of these two cases for a $65 \mathrm{~kg}$ body weight, and this concept was adopted in our analyses. Figure 4 (a) shows the simulated two force vectors acting on the stem and femur for the single leg stance loading cas : compressive force on the top of the stem, $J_{x}=-301(\mathrm{~N}), J_{y}=0(\mathrm{~N})$, $J_{z}=-1282(\mathrm{~N})$ and abducting muscle force on the femur, $M_{x}=381(\mathrm{~N}), M_{y}=0(\mathrm{~N}), M_{z}=1050(\mathrm{~N})$. Figure $4(\mathrm{~b})$ shows the simulated three force vectors acting on the stem and femur for the stair climbing loading case: compressive force on the top of the stem, $J_{x}=-461(\mathrm{~N}), J_{y}=745(\mathrm{~N})$, $J_{z}=-1401(\mathrm{~N})$, abducting muscle force on the femur, $M_{x}=-304(\mathrm{~N}), M_{y}=-306(\mathrm{~N}), M_{z}=-431(\mathrm{~N})$ and another muscle force on the proximal posterior of the femur, $E_{y}=-218(\mathrm{~N})$. 

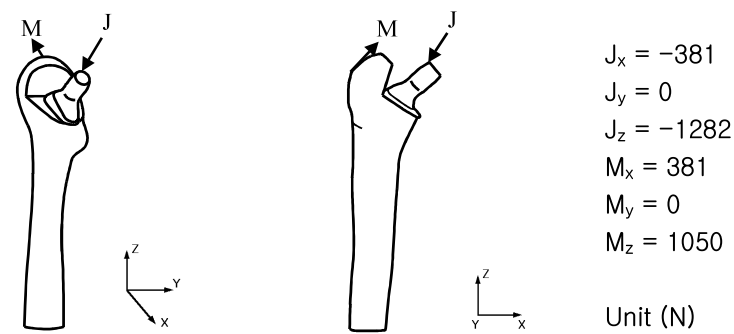

(a) Single leg stance
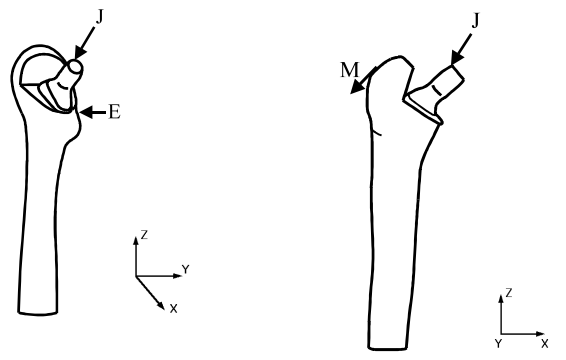

$$
\begin{aligned}
& J_{x}=-461 \\
& J_{y}=745 \\
& J_{z}=-1401 \\
& M_{x}=-304 \\
& M_{y}=-306 \\
& M_{z}=-431 \\
& E_{y}=-218 \\
& \text { Unit (N) }
\end{aligned}
$$

(b) Stair climbing

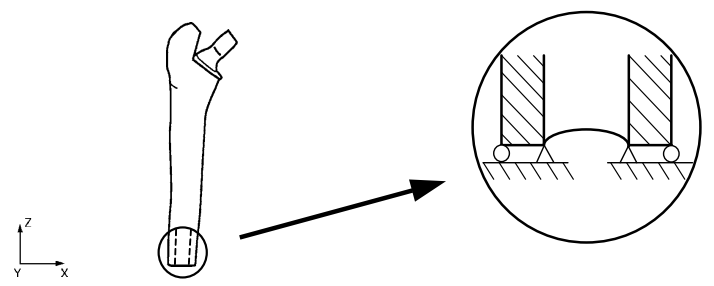

(c) Boundary conditions

Fig. 4 Loading \& boundary conditions
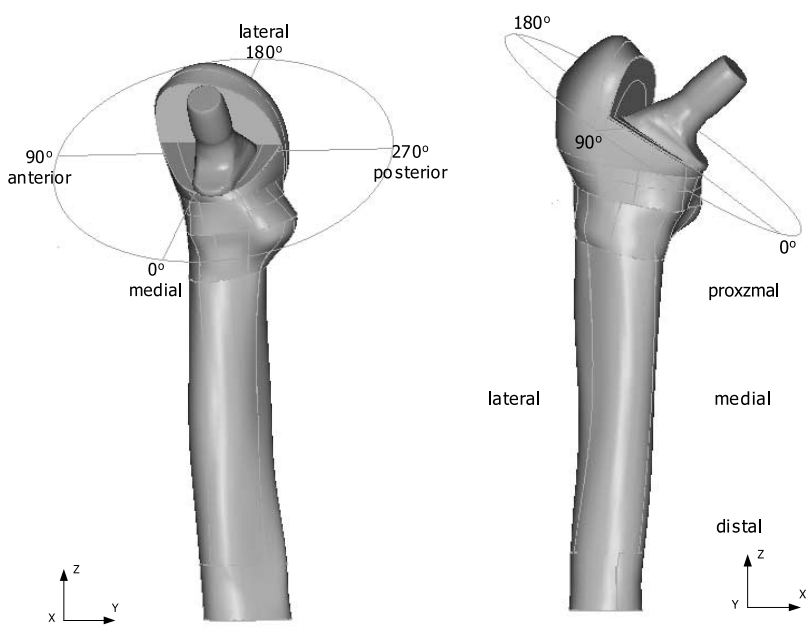

Fig. 5 Terminology of femoral stem

The displacement boundary conditions at the distal end of the femur are shown in Fig. 4 (c). The inner nodes at the distal end of the femur were fixed in all directions, while the outer nodes were fixed only in the $\mathrm{z}$-direction. The directional designations of the model are shown in Fig. 5.

To investigate the initial stability and the stress shielding of the femoral bone with an artificial hip stem for the two loading conditions, the relative displacements between the prosthesis and cancellous bone and the stress distributions of the femur and stem were analyzed by using ABAQUS ${ }^{\mathrm{TM}}$. The relative displacement between the femoral bone and stem was obtained by analyzing the motion of the master node (stem) relative to the motion of the slave surface (femoral bone), and was the resultant magnitude of the displacements in all three directions.

Both the principal stress and the von Mises stress were considered to investigate the stress distribution in the femoral bone and stem. For a porous material such as the femoral bone, the principal stress can be an important index in structural point of view in addition to the von Mises stress. On the other hand, for a metallic material such as the stem, von Mises stress can be a more important index. Therefore, in this paper, both the principal stress and the von Mises stress were considered in the evaluation of the stress distribution in the femoral bone but only the von Mises stress was considered in the evaluation of the stress distribution in the stem.

\section{Results}

The relative displacements between a stem and a femoral bone along the peripheral line located about $3.5 \mathrm{~mm}$ below the collar of the stem are shown in Fig. 6 . For the single leg stance loading case in Fig. 6 (a), the distal filling stem gave the largest relative displacement of $18 \mu \mathrm{m}$ at $204^{\circ}$ in lateral region, while the distal short stem gave the largest relative displacement of $14 \mu \mathrm{m}$ at $39^{\circ}$ in medial region. However, this difference was not significant because the magnitudes of largest relative displacements were very small compared to the threshold value for bony in growth of $100 \mu \mathrm{m}-150 \mu \mathrm{m}$ in both cases. For the stair climbing loading case in Fig. 6(b), the relative displacements for both stems showed similar trends, and the magnitudes of relative displacements of the distal filling stem were generally larger than those of the distal short stem. For example, the largest relative displacements of the distal filling and distal short stems were $44 \mu \mathrm{m}$, and $41 \mu \mathrm{m}$ at $156^{\circ}$, respectively. From Fig. 6 (a) and (b), the distal filling stem showed relatively larger displacements than the distal short stem along the peripheral line in the proximal region. However, the differences were small and thus, not significant. The stair climbing condition produced larger relative displacements than the single leg stance condition did.

The relative displacements along the medial and lateral lines of the femoral bone are shown in Figs. 7 and 8, respectively. In Figs. 7 and 8, only frictional contact region I of the distal short stem was initially in precise contact with the femoral bone, but both frictional contact region I and non-frictional contact region II of the distal filling stem were initially in precise contact with femoral bone, as shown in Fig. 3. 


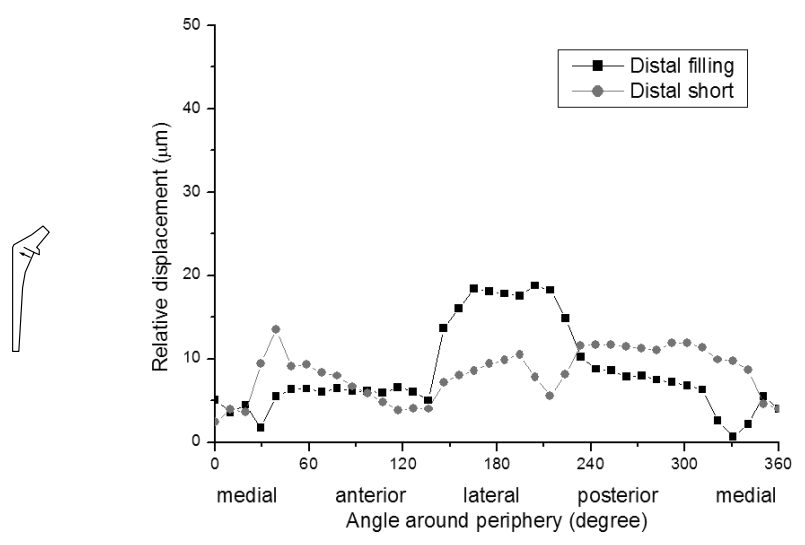

(a) Single leg stance

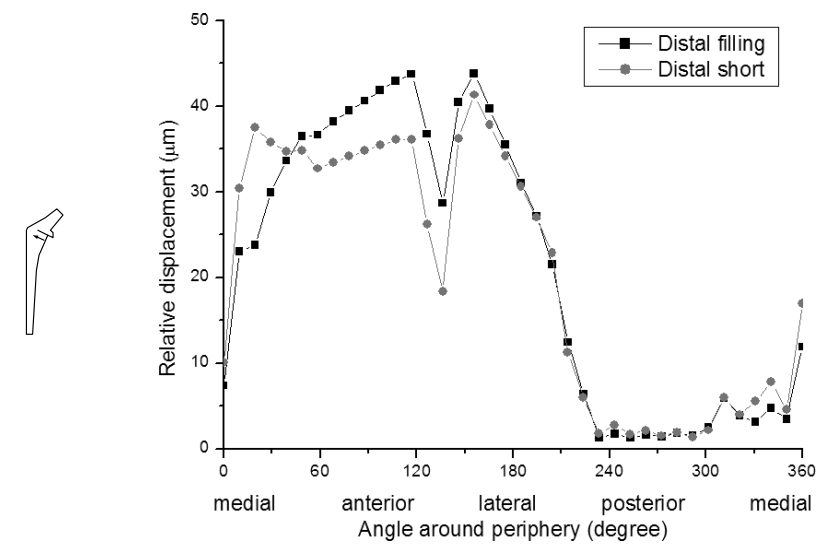

(b) Stair climbing

Fig. 6 Relative displacement along the periphery

Figure 7 (a) shows the magnitudes of the relative displacements of the two types of stems for the case of the single leg stance. The magnitude of the relative displacement of the distal filling stem along the medial line ranged from $5 \mu \mathrm{m}-12 \mu \mathrm{m}$ in the proximal region and became zero in the distal region. The magnitude of the relative displacement of the distal short stem was similar to those of the distal filling stem in the proximal region but increased up to $29 \mu \mathrm{m}$ at frictional contact region I. Figure 7 (b) shows the magnitudes of the relative displacements of the two types of stems for the case of stair climbing. The magnitude of relative displacement for the distal filling stem ranged from $2 \mu \mathrm{m}-19 \mu \mathrm{m}$ in the proximal region and became $5 \mu \mathrm{m}$ in the distal region. The magnitude of the relative displacement for the distal short stem was below $26 \mu \mathrm{m}$ at contact region I, and the relative displacement at distal region II increased and reached up to $142 \mu \mathrm{m}$.

Figure 8 shows the relative displacement between a stem and a femoral bone along a lateral line for the case of single leg stance. Figure 8 (a) shows that the relative displacement for the distal filling stem decreased rapidly from $18 \mu \mathrm{m}$ to $4 \mu \mathrm{m}$ in the proximal region and almost vanished at the distal region. The relative displacement for

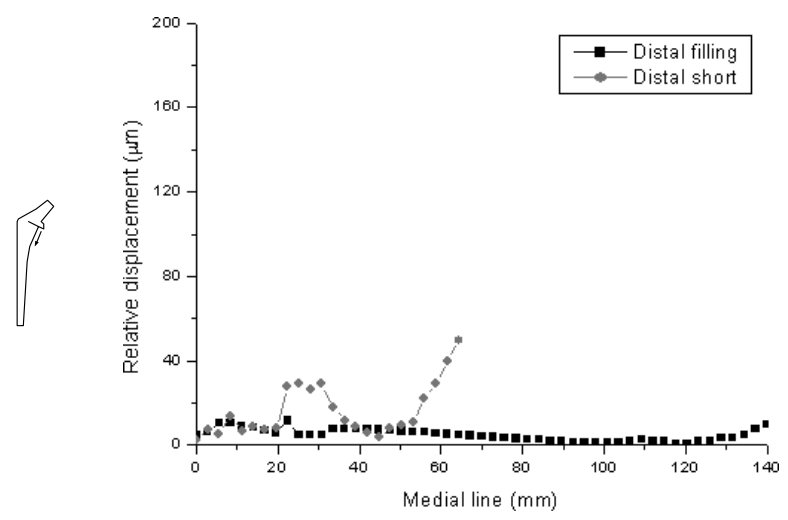

(a) Single leg stance

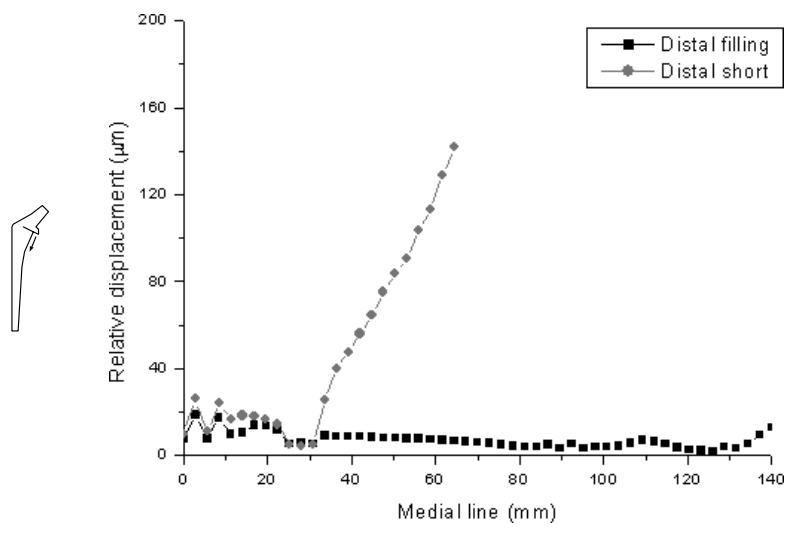

(b) Stair climbing

Fig. 7 Relative displacement along a medial line

the distal short stem was similar to that of the distal filling stem in the proximal region but increased to $17 \mu \mathrm{m}$ at contact region I. In Fig. 8 (b), for the case of stair climbing, relative displacements of both stems showed similar behaviors with the largest relative displacement of $34 \mu \mathrm{m}-$ $36 \mu \mathrm{m}$ in the frictional contact region I. Similarly, the relative displacement for distal short stem at distal region II increased and reached up to $94 \mu \mathrm{m}$. However, since this magnitude is less than the threshold value for bony in growth of $100 \mu \mathrm{m}-150 \mu \mathrm{m}$, this micromotion would not lead to any problem.

The principal stress distributions at the outer surface of cortical bone along medial and lateral lines are shown in Figs. 9 and 10, respectively. In case of single leg stance condition, the largest stress along a medial line was compressive but was tensile along a lateral line, as shown in Figs. 9 (a) and 10 (a). On the other hand, in case of stair climbing condition, the largest stress along a medial line was tensile but was compressive along a lateral line, as shown in Figs. 9(b) and 10 (b). In addition, the magnitudes of the stresses increased as the distal region was approached except at the proximal region where the stem was in contact with the inner side of the femur. This implies that the stresses produced in the femoral bone were basically due to the bending dominant loadings on the fe- 


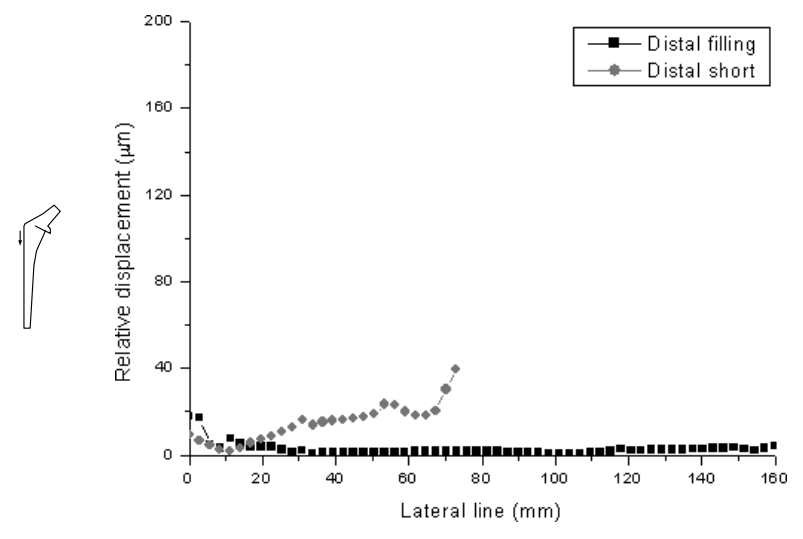

(a) Single leg stance

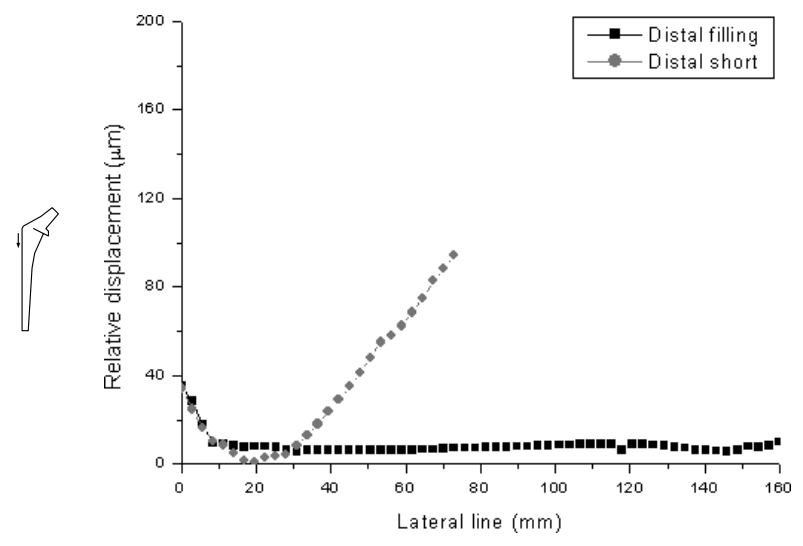

(b) Stair climbing

Fig. 8 Relative displacement along a lateral line

mur. To see the distribution of the other stress components, the von Mises stress distributions at the outer side of the cortical bone along medial and lateral lines were also plotted as shown in Figs. 11 and 12. As shown in Figs. 9-Fig. 12, the von Mises stress distributions in cortical bone were similar to the principal stress distributions. Figure 13 shows the von Mises stress distribution over the outer surface of the femur and stem under the single leg stance, and as can be expected, in the bending dominant loadings, the largest von Mises stress was obtained at the distal region of the femur.

Figure 14 shows the minimum principal stress distributions in cancellous bone of the proximal femur. In Fig. 14, the stress level in most of the regions was below $1 \mathrm{MPa}$, except in the lateral proximal region of the cancellous bone, where the largest stress level was about 4$5 \mathrm{MPa}$ under the stair climbing condition. As shown in Fig. 14, the magnitudes of stresses in the cancellous bone were similar to the results of the finite element analyses by Pancanti et al. ${ }^{(17)}$ Since this region is at the interface between cortical and cancellous bone, the material property in this region, which depends on the apparent density of the cancellous bone, can be considered to be about the average of those of the cortical and cancellous bones.

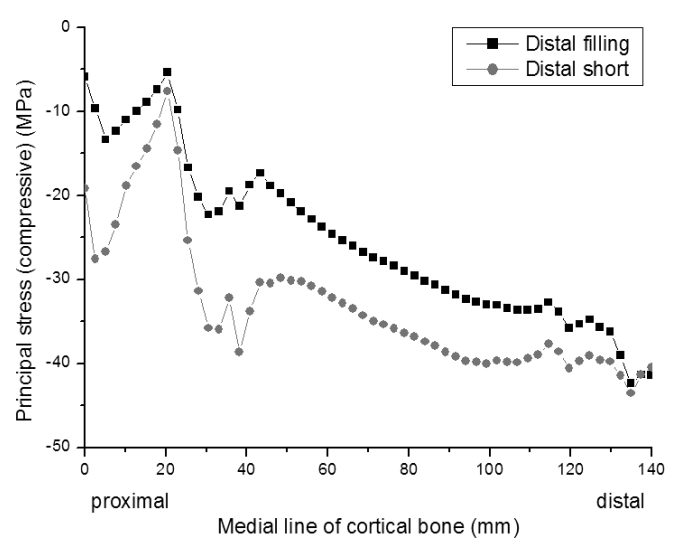

(a) Single leg stance

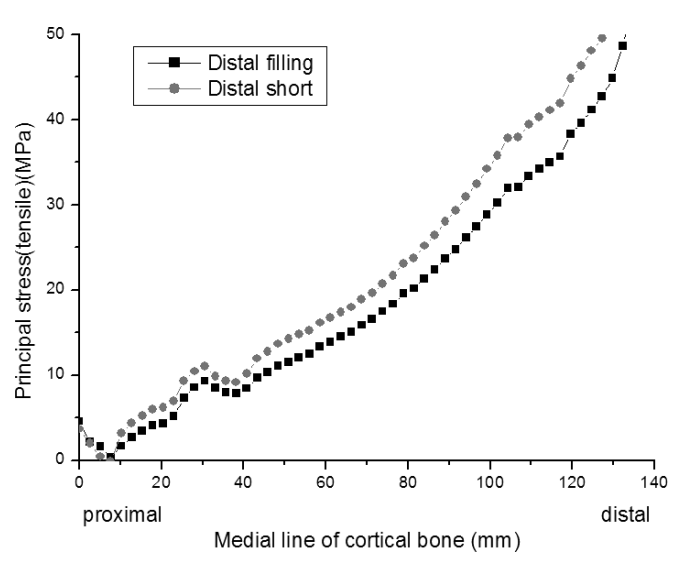

(b) Stair climbing

Fig. 9 Principal stress distribution along a medial line of cortical bone

Therefore, this maximum stress level seems to be below the yield strength of the corresponding region of the cancellous bone.

Figure 15 shows the von Mises stress distribution in a stem along a medial line. The von Mises stress pattern in Fig. 15 clearly shows that the magnitude of stress in the distal filling stem was much larger than that in the distal short stem, except in the proximal region. The distal filling stem carried more stresses in the distal region than in proximal region, while the distal short stem carried stresses only in the proximal region of stem. This result seems reasonable because the distal filling stem carried most of the bending dominant forces, which produced large stresses in the distal region instead of the contact stresses in the proximal region. Moreover, for distal short stem, only the proximal part of the stem was in contact with the femoral bone, and thus, the distal part of the stem was almost stress free. This result can be confirmed in Fig. 16, where the overall von Mises stress distribution in both types of stems under single leg stance is shown. As shown in Fig. 16, the largest stress in the distal filling stem was obtained in the distal region, while that in the distal short stem was obtained in the proximal and medial re- 


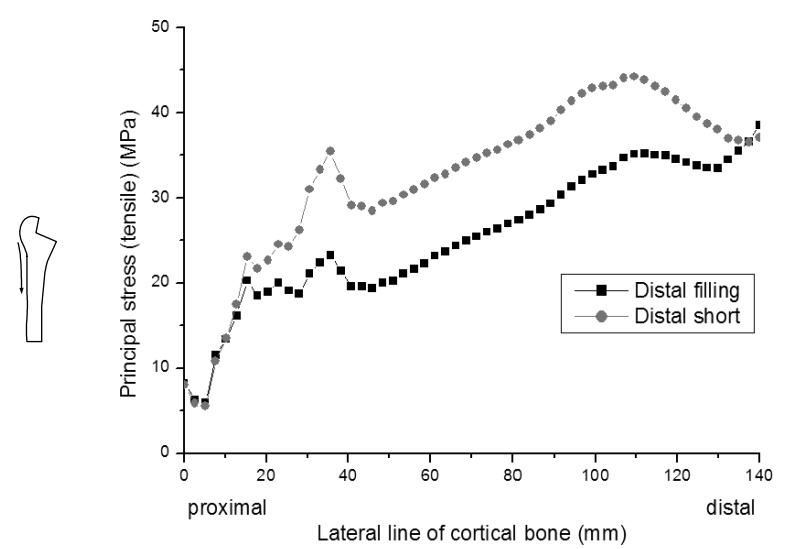

(a) Single leg stance

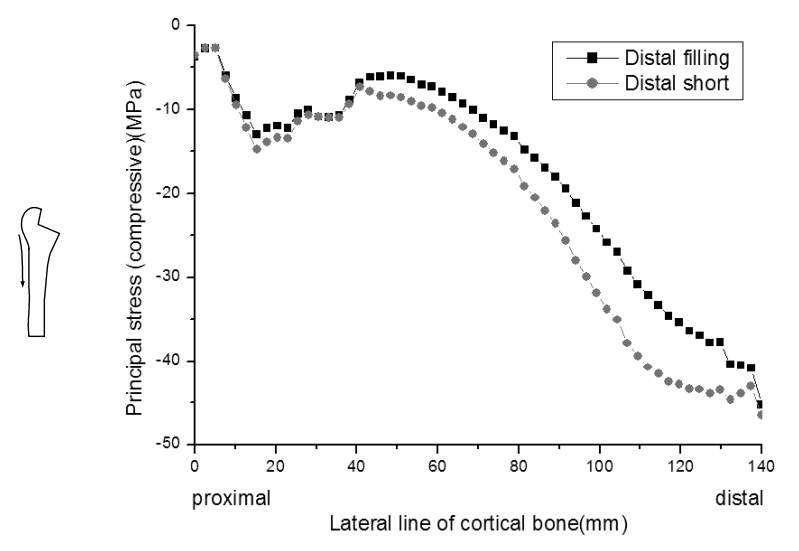

(b) Stair climbing

Fig. 10 Principal stress distribution along a lateral line of cortical bone

gions. The distal short stem had almost no stresses in the distal region. From analyzing the stress patterns at both femoral bone and stems from Fig. 9 to Fig. 16, more stress shielding was likely to appear in distal filling stem for the two loading cases.

\section{Discussions}

The trend of relative displacements between stem and femoral bone along various lines shown in Figs. $6-$ 8 are analogous to the experimental findings of Burke et al. ${ }^{(7)}$ and also the results of the finite element analysis by Biegler et al. ${ }^{(1)}$ Therefore, the results of the analysis has a fair degree of reliability.

From the finite element analysis of the single leg stance for THR, the relative displacement between stem and femoral bone along the peripheral line in proximal region of the stem was maximally $18 \mu \mathrm{m}$ for both types of stem. For the stair climbing condition, the largest relative displacement along the peripheral line in the proximal region of the distal filling stem was $44 \mu \mathrm{m}$, which was a little larger than that of the distal short stem of $41 \mu \mathrm{m}$. On the other hand, the relative displacements along a medial and a lateral line of the distal short stem were generally

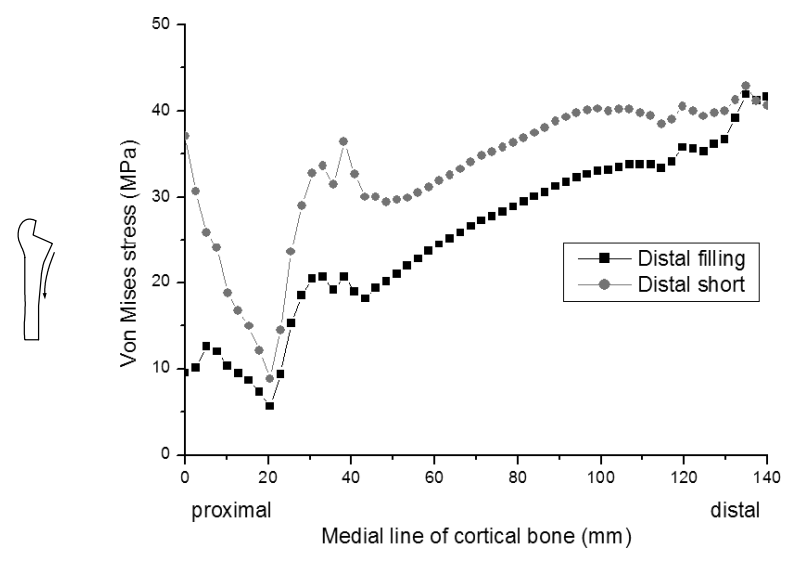

(a) Single leg stance

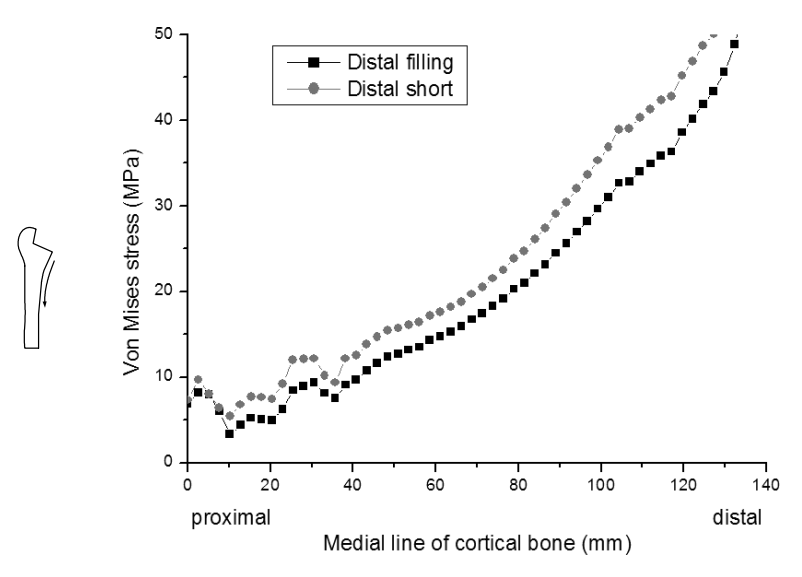

(b) Stair climbing

Fig. 11 Von Mises stress distribution along a medial line of cortical bone

larger than those of the distal filling stem. The largest relative displacement along a medial and a lateral line at frictional contact region I was about $34 \mu \mathrm{m}-36 \mu \mathrm{m}$ for both types of stem under the stair climbing condition. In short, the largest magnitude of the relative displacement at frictional contact region I for both types of stem was below $44 \mu \mathrm{m}$, which was much less than the threshold value for the bony in growth of $100 \mu \mathrm{m}-150 \mu \mathrm{m}$ in the proximal region. These relative displacements were also less than those of other experimental works ${ }^{(18),(19)}$. Therefore, there was not much risk for initial stability in view of separation of a stem from a bone. However, stair climbing requires special attention because the largest relative displacement was obtained under the assumption that the proximal parts of both types of stems were in precise contact with the femoral bone. Consequently, in terms of initial stability, both types of stem would not lead to any initial instability problem, provided that the proximal parts of both stems were in precise contact with the femoral bone.

As for the stress distribution in the femoral bone, different stress patterns either tensile or compressive were found depending on the loading conditions such as single leg stance and stair climbing. The stress produced in the 


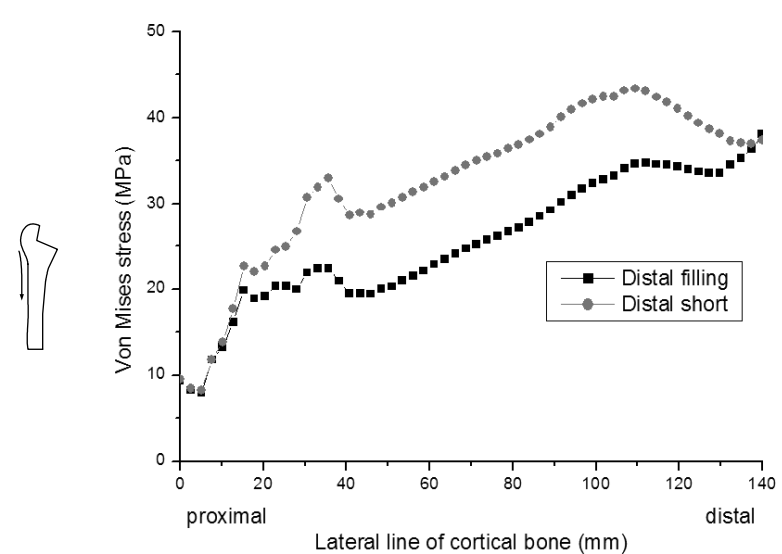

(a) Single leg stance

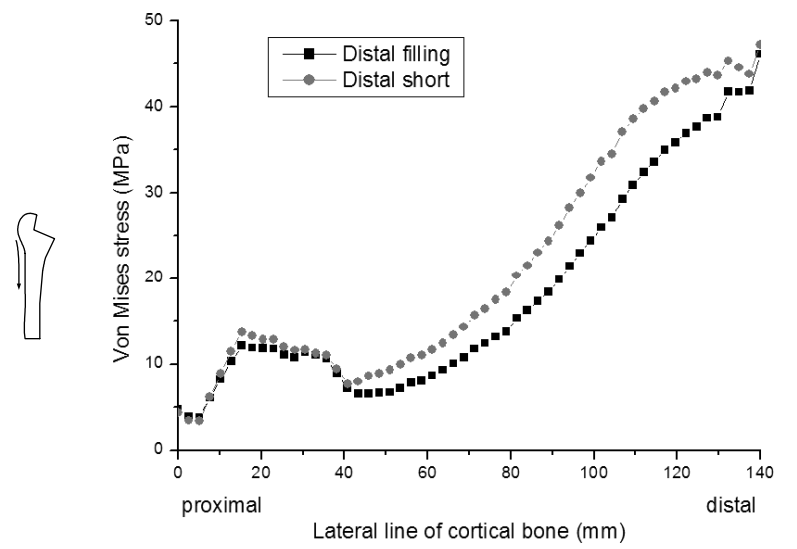

(b) Stair climbing

Fig. 12 Von Mises stress distribution along a lateral line of cortical bone

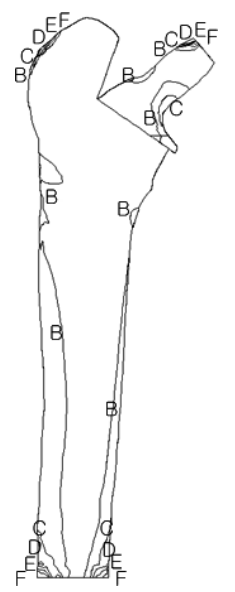

(a) Distal filling stem

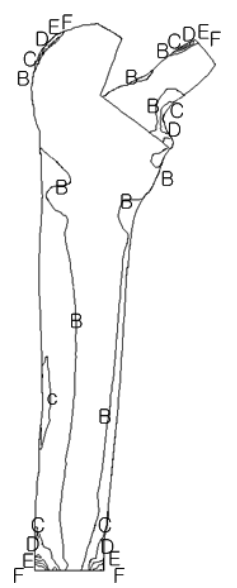

(b) Distal short stem

Fig. 13 Von Mises stress distributions in cortical bone and stem under single leg stance

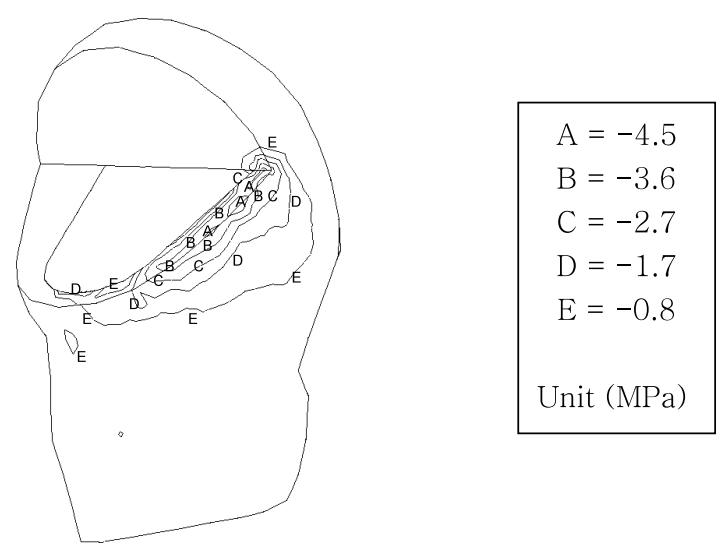

(a) Minimum principal stress distribution in cancellous bone (stair climbing condition, distal flexible stem)
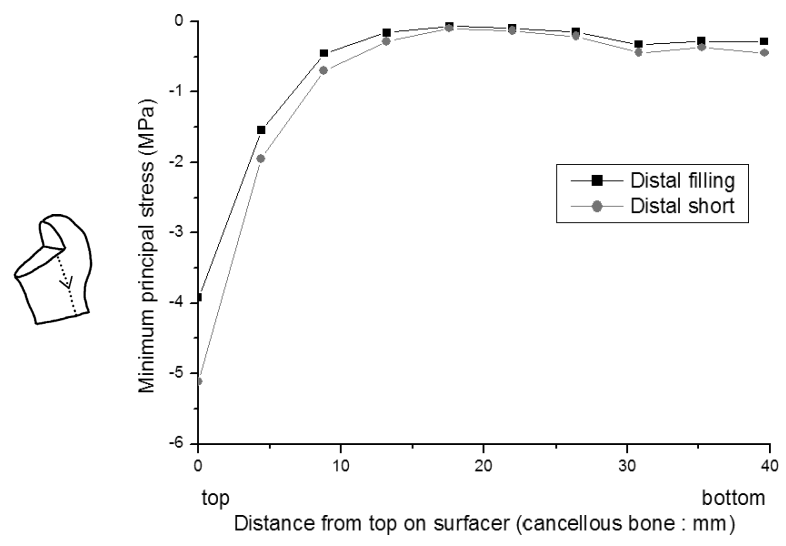

(b) Minimum principal stress along line I (stair climbing condition)

Fig. 14 Minimum principal stress in cancellous bone

femoral bone was basically due to the bending dominant loadings on the femur, except in the proximal and medial regions where the inner side of the femur was in contact with the stem.

As shown in Figs. 9 and 11 for single leg stance, the magnitudes of principal and von Mises stresses at the outer surface of the cortical bone along a medial line were larger both in the proximal and in the distal region for the distal short stem than those for the distal filling stem, although for stair climbing condition, the difference was small. Figures 10 and 12 show the principal and von Mises stresses at the outer side of the cortical bone along a lateral line. As shown in Figs. 10 and 12, the principal and von Mises stresses in the distal short stem were larger than those in the distal filling stem only in the distal region. Therefore, in case of the distal short stem, the femoral bone carried more stresses than the distal filling stem, especially in the proximal and medial regions. This proximal region along the medial line is an important region of the femoral bone where stress shielding is most likely to appear, and is a region where the stem can dissociate from the femur.

Consequently, in terms of initial stability, both types 


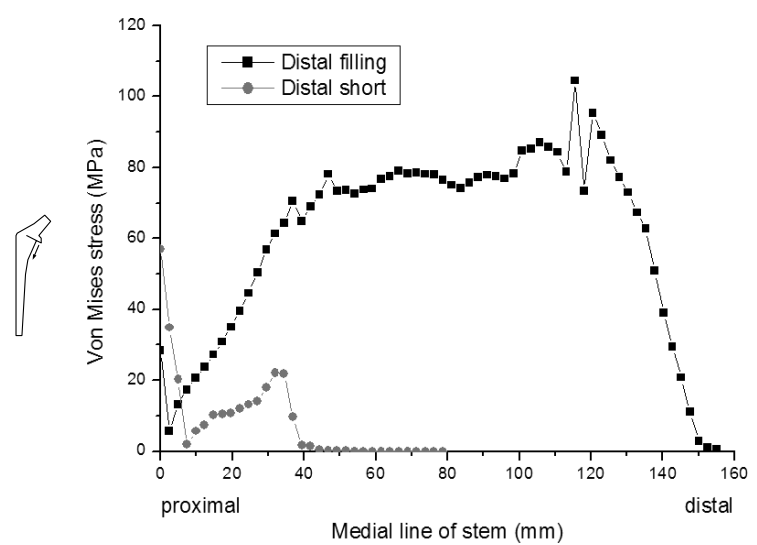

(a) Single leg stance

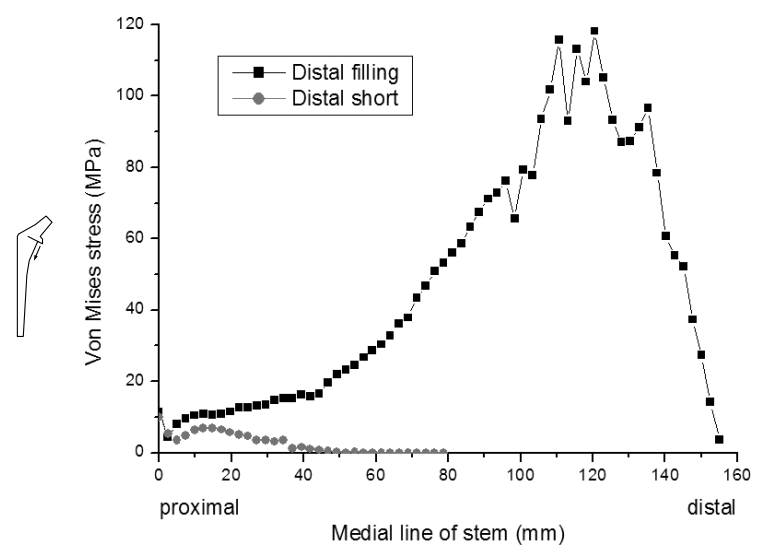

(b) Stair climbing

Fig. 15 Von Mises stress distribution along a medial line of stem

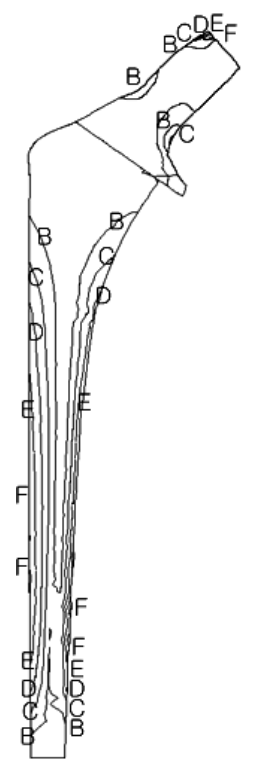

(a) Distal filling stem

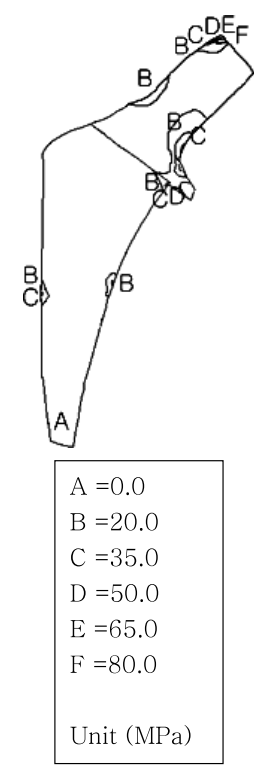

(b) Distal short stem
Fig. 16 Von Mises stress distributions in stems under single leg stance

of stems seemed to satisfy the required conditions such that the largest relative displacements between a stem and a femoral bone in the proximal region was about $36 \mu \mathrm{m}-$ $44 \mu \mathrm{m}$ under the stair climbing condition. But in the viewpoint of stress distribution, both at the femoral bone and stem, the distal short stem produced less stress shielding at the proximal femoral bone than the distal filling stem.

\section{References}

( 1 ) Biegler, F.B., Reuben, J.D., Harrigan, T.P., Hou, F.J. and Akin, J.E., Effect of Porous Coating and Loading Conditions on Total Hip Femoral Stem Stability, J. Arthroplasty, Vol.10, No.6 (1995), pp.839-847.

(2) Chae, S.W., Jeong, J.H. and Kim, S.K., Biomechanical Characteristics of a Straight and a Curved Femoral Stem in Cementless Artificial Hip Joint, Transactions of the Korean Society of Mechanical Engineers, Vol.22, No.5 (1998), pp.804-813.

( 3 ) Keyak, J.H., Rossi, S.A., Jones, K.A. and Skinner, H.B., Prediction of Femoral Fracture Load Using Automated Finite Element Modeling, J. Biomechanics, Vol.31 (1998), pp.125-133.

( 4 ) Rohlman, A., Cheal, E.J., Hayes, W.C. and Bergmann, G., A Non Linear Finite Element Analysis of Interface Conditions in Porous Coated Hip Endoprostheses, J. Biomechanics, Vol.21 (1988), pp.605-611.

( 5 ) Van Rietbergen, B., Huiskes, R., Weinans, H., Sumner, D.R., Turner, T.M. and Galante, J.O., The Mechanism of Bone Remodeling and Resorption around PressFitted THA Stems, J. Biomechanics, Vol.26, No.4 (1993), pp.369-382.

( 6 ) Huiskes, R., Weinans, H. and Van Rietbergen, B., The Relationship between Stress Shielding and Bone Resorption around Total Hip Stems and the Effects of Flexible Materials, Clinical Orthopaedics and Related Research, Vol.274 (1992), pp.124-134.

( 7 ) Burke, D.W., O’Connor, D.O., Zalenski, E.B., Jasty, M. and Harris, W.H., Micromotion of Cemented and Uncemented Femoral Components, J. Bone Joint Sur. [Br.], Vol.73-B, No.1 (1991), pp.33-37.

( 8 ) Skinner, H.B., Kilgus, D.J., Keyak, J., Shimaoka, E.E., Kim, A.S. and Tipton, J.S., Correlation of Computed Finite Element Stresses to Bone Density after Remodeling around Cementless Femoral Implants, Clinical Orthopaedics and Related Research, No.305 (1994), pp.178-189.

( 9 ) Morey, B.F., Short-Stemmed Uncemented Femoral Replacement Component, Clinical Orthopaedics and Related Research, No.249 (1989), pp.169-175.

(10) Huskies, R., Snijders, H., Vroemen, W., et al., Fixation Stability of a Short Cementless Hip Prosthesis, Orthopaedic Transactions, Vol.10 (1986), p.466.

(11) I-DEAS User's Manual, Master Series, SDRC Inc.

(12) ABAQUS Standard User's Manual for Version 6.3, Hibbitt, Karlsson \& Sorensen Inc.

(13) Keaveny, T.M. and Bartel, D.L., Effects of Porous Coating and Collar Support on Early Load Transfer for a Cementless Hip Prosthesis, J. Biomechanics, Vol.26 (1993), pp.1355-1368.

(14) Rubin, P.J., Rakotomanana, R.L., Leyvraz, P.F., Zysset, P.K., Curnier, A. and Heegard, J.H., Friction Interface Micromotions and Anisotropic Stress Distribution 
in a Femoral Total Hip Component, J. Biomechanics, Vol.26 (1993), pp.725-738.

(15) Keaveny, T.M. and Bartel, D.L., Mechanical Consequence of Bone Ingrowth and Fibrous Tissue Encapsulation for a Cementless Hip Prothesis in the LongTerm, Trans 38th ORS, Vol.17 (1992), p.73.

(16) Harrigan, T.P. and Harris, W.H., A Three-Dimensional Non-Linear Finite Element Study of the Effect of Cement-Prosthesis Debonding Incremented Fomoral Total Hip components, J. Biomechanics, Vol.24 (1991) pp.1047-1058.

(17) Pancanti, A., Bernakiewiz, M. and Viceconti, M., The Primary Stability of a Cementless Stem Varies between
Subjects as Much as between Activities, J. Biomechanic, Vol.36 (2003), pp.777-785.

(18) Christian, G., Wolfram, S., Volker, V., Christopher, P., Lutz, C. and Jörn, S., Primary Stability in Cementless Femoral Stems; Custom-Made versus Conventional Femoral Prosthesis, J. Clinical Biomechanics, Vol.17 (2002), pp.267-273.

(19) Bühler, D.W., Oxland, T.R. and Nolte, L.P., Design and Evaluation of a Device for Measuring ThreeDimensional Micromotions of Press-Fit Femoral Stem Prostheses, J. Med. Eng. Phys., No.2 (1997), pp.187199. 